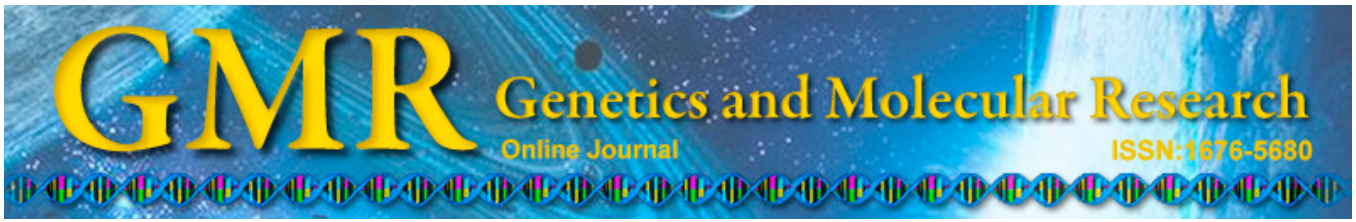

\title{
Novel bioinformatic identification of differentially expressed tissue-specific and cancer-related proteins from the Human Protein Atlas for biomarker discovery
}

\author{
X.-X. Liu and F.-J. Liu \\ Central Laboratory, Yu-Huang-Ding Hospital/Qingdao University, Yantai, \\ Shandong, China \\ Corresponding author: F.-J. Liu \\ E-mail: sdstemcell@126.com
}

Genet. Mol. Res. 14 (2): 4557-4565 (2015)

Received July 14, 2014

Accepted November 26, 2014

Published May 4, 2015

DOI http://dx.doi.org/10.4238/2015.May.4.14

\begin{abstract}
Identification of cancer-associated and tissue-specific proteins is important for research on carcinogenesis mechanisms and biomarker discovery. Here we performed a new strategy to identify candidate cancer proteins by mining immunohistochemistry protein profiles. Proteins with quantitative values from 14 normal tissues and their corresponding cancer tissues were compared and analyzed using bioinformatics. The final results included identification of tissue-specific proteins and differentially expressed proteins in different cancer types that are primarily involved in energy metabolism and cell invasion. From the tissue-specific proteins, secreted and membrane proteins were further screened and functionally clustered. These primarily belonged to the gene families of endogenous ligands, cluster of differentiation molecules, and solute carriers, and were mainly involved in the processes of cell motility, hormone metabolism, adhesion, and transport. Further studies are warranted to validate the candidates identified herein and substantiate the suggested enriched functions. The results
\end{abstract}


from this study might provide a reliable resource to study underlying carcinogenesis mechanisms and discover potential cancer targets for the development of therapeutic targets and of early diagnosis and disease response markers.

Key words: Cancer; Bioinformatics; Immunohistochemistry; Biomarkers

\section{INTRODUCTION}

Carcinogenesis is a complex and unpredictable process that involves many molecular alterations leading to deficits in multiple cellular signaling pathways (Capaccione and Pine, 2013). Molecules involved in this process may be used as potential biomarkers to reflect disease state and reveal its underlying pathogenesis (Liu et al., 2012a,b). Therefore, cancer biomarker discovery is crucial for progressive research in cancer biology and clinical application. Biomarkers may include DNA, RNA, or protein molecules, with proteins being considered the most promising (Polanski and Anderson, 2007). Biomarkers in each tissue should have differential expression levels or activities between different disease states, thus serving as a measured or evaluated profile for reflecting normal biological processes, pathogenic processes, or responses to treatment (Prassas et al., 2012).

With the advent and development of proteomic biotechnologies, many potential protein biomarkers have been identified by differential proteomic techniques in various cancer types (Brinton et al., 2012; Honda et al., 2013). Some of these proteins were clustered and manifested in different databases, such as dbDEPC (http://lifecenter.sgst.cn/dbdepc/index.do), which describes differentially expressed proteins in human cancers, GeMDBJ Proteomics (https://gemdbj.nibio. go.jp/dgdb/DigeTop.do), which includes an integrated proteome database for cancer research, CanProVar (http://bioinfo.vanderbilt.edu/canprovar/), which was designed as a human cancer proteome variation database, and the Human Protein Atlas (HPA, http://www.proteinatlas.org/), which contains quantified immunochemistry results of normal and cancer tissues based on antibody proteomics. By comparing and re-analyzing these data, we can obtain new insight into the research of underlying mechanisms of carcinogenesis and discovery of cancer biomarkers. However, due to the heterogeneity of experimental methods and specimen preparation between laboratories (Issaq et al., 2011; Heckman-Stoddard, 2012), the results obtained from proteomic analyses lack good reproducibility and require further verification and validation before they can be used in clinical detection and to explain underlying mechanisms.

Alteration of protein expression can lead to disturbances in molecular function or pathways regulating cell growth, survival, or metastasis (Polanski and Anderson, 2007). Molecules that exhibit changes in a specific cancer can be used as biomarkers for detection, diagnosis, or prognosis. To perform a reliable functional analysis and identify potential cancer biomarkers, the proteomic variation data were normally verified by Western blot or immunohistochemistry. Immunohistochemistry plays vital role in histological diagnosis, and the immunohistochemical markers could be used for estimating prognosis and predicting therapy response (Ordóñez, 2013). The HPA is built based on immunohistochemistry data, and provides a reliable proteomic resource for biomarker discovery (Pontén et al., 2011). It is a powerful platform not only to provide immunohistochemical mapping but also to provide quantitative protein expression profiles across different tissues. The information generated using the HPA 
allows the screening for differential protein profiles across different tissues. In the present study, we identified differentially expressed cancer proteins and tissue-specific proteins by re-analyzing HPA datasets. Our strategy compared proteins quantitatively between normal and cancer tissues by selecting up- or down-regulated proteins in cancers, and compared the proteins across different tissues for the selection of proteins highly specific to or strongly expressed in a single tissue. Secreted and membrane proteins were further selected to prioritize candidates for future validation and verification. The results might provide new insight into cancer biology research, leading to a better understanding of cancer progression and facilitating cancer biomarker discovery.

\section{MATERIAL AND METHODS}

\section{Data collection}

Staining profiles for proteins in normal and cancer tissues were downloaded from the HPA. The normal and cancer tissues included breast, cervix, colon, larynx, liver, lung, ovary, pancreas, prostate, kidney, stomach, testis, thyroid gland, and urinary bladder samples. The expression level of each protein was then graded into four levels: strong: $>75 \%$; moderate: $25-75 \%$; weak: $<25 \%$, and negative: $0 \%$ for use as retrieval parameters. The differentially expressed proteins were defined as those that exhibited a change in expression of more than two levels between the previously described groups. The resulting proteins in each cancer type were grouped into up- and down-regulated proteins. The specifically expressed proteins referred to proteins with higher expression of more than two levels across different tissue types.

\section{Functional annotation clustering analysis of differentially expressed proteins}

The protein identifiers were uploaded to the Database for Annotation Visualization and Integrated Discovery (DAVID; http://david.abcc.ncifcrf.gov/) and enrichment analyses of the Gene Ontology (GO) terms, including the biological process and molecular function, were performed using the functional clustering annotation tools. The default options with high classification stringency were used. Finally, the cluster names were extracted from the most biologically relevant GO term that was assigned to that cluster.

\section{Over-representation analysis of specifically expressed proteins}

The over-representation analyses of GO terms, including biological processes and molecular function, were performed using the functional tool of ConsensusPathDB-human (http://cpdb.molgen.mpg.de/CPDB), which is a molecular functional interaction database. The GO level -2 and -3 categories were selected, and we set the P value cutoff at 0.01 .

\section{Analysis of secreted and membrane proteins}

The secreted and membrane proteins were screened through tools in LOCATE (http:// locate.imb.uq.edu.au/), which is a curated database for describing membrane organization. The membrane proteins included types I, II, and III proteins. 


\section{RESULTS}

\section{Identification of differentially expressed proteins in different cancer types}

By comparing the quantitative immunohistochemistry results across normal and cancer tissues with a 2-level difference, up- and down-regulated proteins in different cancers were identified. As displayed in Figure 1, the largest number of up-regulated proteins were identified in ovarian cancer (1671 proteins), followed by renal cancer (1015 proteins), and the largest number of down-regulated proteins were identified in stomach cancer (4370 proteins), followed by testis (3673 proteins), lung (3055 proteins), and pancreatic (3046 proteins) cancers.

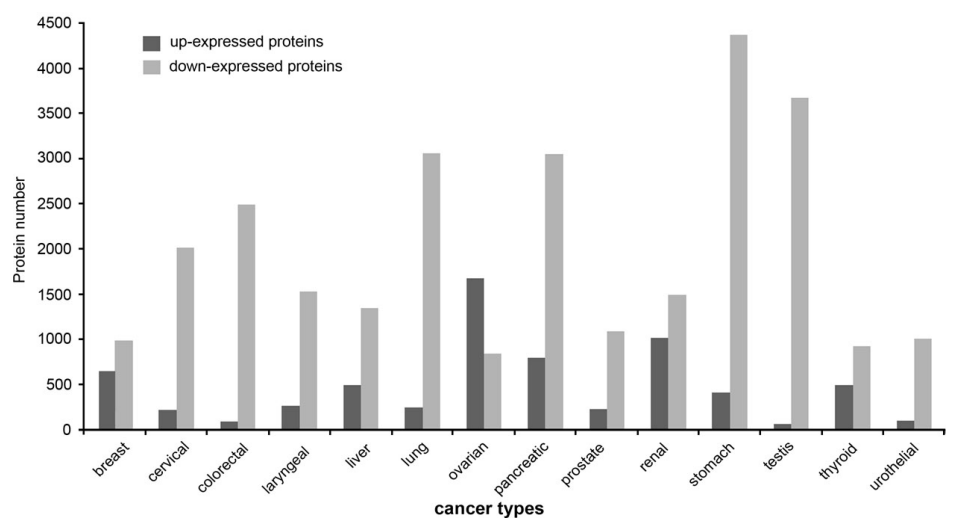

Figure 1. Distribution of up-regulated and down-regulated proteins in different cancer types.

\section{Identification of specifically expressed proteins across different normal or cancer tissues}

The unique proteins that were highly specific to or strongly expressed in certain cancer or normal tissues were identified (Table 1). The largest number of unique cancer proteins was identified in the thyroid gland (103 proteins), and the largest number of unique normal tissue proteins was identified in the testis (123 proteins). Urinary bladder had few unique proteins in either normal or cancer tissues.

\section{Secreted and membrane proteins}

We found that secreted and membrane proteins from the specifically expressed proteins appeared to be the most promising biomarkers. By retrieving the subcellular localization database, secreted and membrane proteins in each tissue were identified as displayed in Table 2. In cancer tissues, a total of 45 secreted proteins and 93 membrane proteins were identified. Many of the secreted proteins (13) were present in pancreatic cancer, and many of the membrane proteins were present in thyroid cancer. A total of 59 secreted proteins and 89 membrane proteins were selectively identified in normal tissues, and the largest number of secreted (11) and membrane (19) proteins were present in the testis. These secreted proteins primarily belonged to the gene family of endogenous ligands (6) and cluster of differentiation (CD) molecules (5). The membrane proteins were mainly from the gene families of CD molecules (16) and solute carriers (15). 
Table 1. Number of proteins specifically expressed in different tissues.

\begin{tabular}{lcr}
\hline Tissue & & Specific proteins (N) \\
\cline { 2 - 3 } & Cancer tissue & Normal tissue \\
\hline Breast & 14 & 19 \\
Cervix & 3 & 26 \\
Colon & 35 & 60 \\
Kidney & 25 & 12 \\
Larynx & 36 & 10 \\
Liver & 49 & 42 \\
Lung & 2 & 34 \\
Ovary & 5 & 5 \\
Pancreas & 77 & 51 \\
Prostate & 38 & 18 \\
Stomach & 14 & 30 \\
Testis & 28 & 123 \\
Thyroid gland & 103 & 10 \\
Urinary bladder & 2 & 6 \\
\hline
\end{tabular}

Table 2. Secreted and membrane proteins specifically expressed in different normal vs cancer tissues.

\begin{tabular}{|c|c|c|c|c|}
\hline \multirow[t]{2}{*}{ Tissues } & \multicolumn{2}{|r|}{ Cancer } & \multicolumn{2}{|c|}{ Normal } \\
\hline & Secreted proteins & Membrane proteins & Secreted proteins & Membrane proteins \\
\hline Breast & $\begin{array}{l}\text { FBLN1, MTTP, STT3B, } \\
\text { SCGB2A2 }\end{array}$ & PCDH19, SLC15A3 & PIP, CHSY1, CCL25 & DPP6, PRLHR, ZDHHC16 \\
\hline Cervix & - & - & SPINK5, Slpi, CELA2A & KRT6C, IQCF1, KRT6B, PLVAP, \\
\hline Colon & DPEP1, CDHR5, SIRPB1 & $\begin{array}{l}\text { SIRPB1, SLC17A6, GPA33, } \\
\text { Gpr82, CDHR5, FASLG }\end{array}$ & $\begin{array}{l}\text { CDHR5, CA4, PYY, REG4, } \\
\text { CLCA1, vWF, UMOD, ZG16 }\end{array}$ & $\begin{array}{l}\text { GGT5, MUC13, UGT2B10, UGT2A3, } \\
\text { UGT2B28, UGT2B7, SGCD, } \\
\text { CNTNAP2, SELE, GPR61, PIGO, } \\
\text { ENTPD1, CADM3, RTN3, LPHN2 }\end{array}$ \\
\hline Larynx & CD99L2, ANGPTL3 & $\begin{array}{l}\text { KIRREL, KRT6B, CYB561D1, } \\
\text { SLC5A7, RHBDD2, SLC10A6 }\end{array}$ & GLB1L, NTN3, SFRP2, RNASE2 & TMEM117, MANBAL \\
\hline Kidney & VCAN, CST7 & $\begin{array}{l}\text { CDH16, CST7, GGTLC2, } \\
\text { GGT4P, NIM1 }\end{array}$ & APOA1, APOB, PTPRO, & $\begin{array}{l}\text { KIRREL, CRIM1, PODXL, ITGA8, } \\
\text { PTPRO, NPHS2, KIAA0317 }\end{array}$ \\
\hline Liver & $\begin{array}{l}\text { LRP1, F2, LYZL4, LOXL3, } \\
\text { MUC15, PRSS38 }\end{array}$ & $\begin{array}{l}\text { MUC15, LRP1, SLC27A2, SGCZ, } \\
\text { CCR3, CREB3L2, TFR2, KCND1, } \\
\text { S1PR5, ZDHHC1, OR56B1 }\end{array}$ & CRP, PON3 & $\begin{array}{l}\text { S1PR5, TFR2, ABCC2, SLCO1B3, } \\
\text { GPR12, CYP1A2 }\end{array}$ \\
\hline Lung & - & FAM57B & LECT2, CTSG, ITGB2, SFTPA1 & $\begin{array}{l}\text { MPO, ITGAM, ITGB2, MRC1, } \\
\text { NUP205, DOCK5, PAQR5, CD163, } \\
\text { CYBA, ALOX5AP }\end{array}$ \\
\hline Ovary & - & WT1, ADIPOR2 & CD55 & CD55 \\
\hline Pancreas & $\begin{array}{l}\text { COL4A2, DCN, PIP, CSH1, } \\
\text { FGF18, COL6A3, SPARCL1, } \\
\text { ACE, AGTR1, TPSAB1, } \\
\text { TFF2, CALR3, RNASE2 }\end{array}$ & $\begin{array}{l}\text { PLLP, MS4A1, CD19, OR4F21, } \\
\text { SLC22A1, CD34, CACNA2D1, } \\
\text { EMB, LYZL2, B3GNT4, SGCB, } \\
\text { CMTM5, RGMB, CPNE9 }\end{array}$ & $\begin{array}{l}\text { DBC1, REG1A, CPA1, IAPP, } \\
\text { TFF3, CPA2, GCG }\end{array}$ & $\begin{array}{l}\text { CCDC107, DGCR2, TFF3, LOC150763, } \\
\text { PIGM, BEST2, MBOAT1, LPPR1, } \\
\text { SV2A, TMEM145 }\end{array}$ \\
\hline Prostate & $\begin{array}{l}\text { CPE, PLAT, KLK2, ACPP, } \\
\text { HEXB, KLK3, PLAT }\end{array}$ & $\begin{array}{l}\text { KIAA1324, PLAT, ACPP, HEXB, } \\
\text { FOLH1, SLC3A1, AQP8, OR2AK2, } \\
\text { RAP1GAP }\end{array}$ & $\begin{array}{l}\text { KLK4, KLK2, ACPP, HTRA4, } \\
\text { KLK3 }\end{array}$ & ACPP, FOLH1, TMPRSS13, CD38 \\
\hline Stomach & BMP4, VEGFB & GPR15, DISP1 & $\begin{array}{l}\text { C1RL, TGFB1, PGC, TFF2, } \\
\text { GIF, TMEM178 }\end{array}$ & $\begin{array}{l}\text { LINGO1, IGSF3, TCTN3, SLC36A2, } \\
\text { TMEM178 }\end{array}$ \\
\hline Testis & - & ALPL, DSCAM, TPRA1 & $\begin{array}{l}\text { ACRV1, ACR, ACRBP, PTN, } \\
\text { BMP8B, GLB1L, INSL6, INHA, } \\
\text { LYZL6, SPINK2, FMR1NB }\end{array}$ & $\begin{array}{l}\text { TMEM132D, TEX264, TTC21A, } \\
\text { TMEM102, CYP19A1, TBC1D9, } \\
\text { SUN5, SLC2A8, TEX101, MYCBP2, } \\
\text { PTCHD3, NKAIN3, ADAM2, KCNG4, } \\
\text { OPRM1, SLC35E4, MYCBP2, } \\
\text { CLDN11, SLC35E4 }\end{array}$ \\
\hline $\begin{array}{l}\text { Thyroid } \\
\text { gland }\end{array}$ & $\begin{array}{l}\text { C2ORF } 40 \text {, TPO, AMELY, } \\
\text { MAMDC } 2 \text {, TG }\end{array}$ & $\begin{array}{l}\text { CLSTN3, SUSD1, CD3G, TPO, } \\
\text { PTPRH, PEAR1, HEPACAM2, } \\
\text { ACVRL1, MRC2, ADAM19, } \\
\text { CLSTN3, NBEA, TMPRSS9, } \\
\text { HS6ST2, NOX4, PCDHB5, CABP7, } \\
\text { C17ORF } 68, \text { BCL2, SLC23A1, ADRA1A, } \\
\text { TMEM204, RETSAT, CNIH2, SLCO2A1, } \\
\text { ADRA1A, CMKLR1, KCNK6, UPK1A, } \\
\text { LRRC55, NKAIN2, LPCAT2, SLC25A31 }\end{array}$ & TPO, TG, CPQ & TPO, CDH16, PGCP, SLC17A2 \\
\hline $\begin{array}{l}\text { Urinary } \\
\text { bladder }\end{array}$ & FAT2 & KCNE1 & - & UPK3A \\
\hline
\end{tabular}




\section{Comparison of normal testis-specific proteins with cancer-specific proteins}

The specifically expressed testis proteins selected in this study were compared with specifically expressed cancer proteins. ANKIB1 was specifically expressed in breast cancer, and TEX264 was specifically expressed in colorectal cancer. SPATA7 was commonly highly expressed in breast and ovarian cancers. Notably, except for HSPA4L in pancreatic cancer and MBD3L1 in stomach cancer, 24 proteins were commonly highly expressed in pancreatic and stomach cancers.

\section{Ontological analysis}

To map the major functional categories, the up-regulated proteins in every cancer type were grouped into several functional clusters using the functional annotation clustering tool DAVID (Table 3). Certain enriched functional clusters were common in more than three cancer types, including cell cycle, mitochondrion, cytoskeleton, cell adhesion, protein localization, and tight junction proteins. These prominent functional clusters were primarily involved in the biological processes of energy metabolism and cell invasion.

Table 3. Enriched functional clusters of up-regulated proteins in different cancers.

\begin{tabular}{|c|c|c|c|c|c|c|}
\hline Breast cancer & Cervical cancer & Colorectal cancer & Head and neck cancer & Liver cancer & Lung cancer & Ovarian cancer \\
\hline $\begin{array}{l}\text { ATP binding } \\
\text { Protein localization } \\
\text { Cytoplasmic vesicle } \\
\text { Proteolysis } \\
\text { Cell cycle } \\
\text { Angiogenesis } \\
\text { Apoptosis }\end{array}$ & $\begin{array}{l}\text { Cell cycle } \\
\text { DNA replication } \\
\text { Cell junction } \\
\text { Golgi apparatus } \\
\text { Cyclin }\end{array}$ & $\begin{array}{l}\text { Cell cycle } \\
\text { DNA packaging } \\
\text { Immunoglobulin-like } \\
\text { Apoptosis }\end{array}$ & $\begin{array}{l}\text { Regulation of lipid } \\
\text { metabolic processes } \\
\text { Epidermal development } \\
\text { Cell junction } \\
\text { Cyclin } \\
\text { Regulation of Wnt } \\
\text { receptor signaling } \\
\text { pathway } \\
\text { Kinase binding }\end{array}$ & $\begin{array}{l}\text { RNA processing } \\
\text { DNA replication } \\
\text { Ribosome } \\
\text { DNA repair } \\
\text { Kinase binding } \\
\text { Chaperone } \\
\text { Exonuclease activity } \\
\text { Cell cycle } \\
\text { Protein localization } \\
\text { Tight junction }\end{array}$ & $\begin{array}{l}\text { Tight junction } \\
\text { ATPase activity } \\
\text { Mitochondrion } \\
\text { Cytoskeleton } \\
\text { Cell cycle }\end{array}$ & $\begin{array}{l}\text { Mitochondrion } \\
\text { Ribosome } \\
\text { Glycosylation } \\
\text { Tight junction } \\
\text { Cell cycle } \\
\text { Lipid metabolism } \\
\text { Protein localization } \\
\text { ATPase activity } \\
\text { tRNA processing }\end{array}$ \\
\hline Pancreatic cancer & Prostate cancer & Renal cancer & Stomach cancer & Testis cancer & Thyroid cancer & Urothelial cancer \\
\hline $\begin{array}{l}\text { Cell adhesion } \\
\text { Extracellular region } \\
\text { Cytoskeleton } \\
\text { Membrane protein } \\
\text { Myofibril assembly } \\
\text { Cell-matrix adhesion } \\
\text { Peptidase inhibitor } \\
\text { activity } \\
\text { Oxidation reduction } \\
\text { Regulation of cell } \\
\text { migration }\end{array}$ & $\begin{array}{l}\text { Transcription } \\
\text { factor activity } \\
\text { Cell cycle } \\
\text { tRNA processing } \\
\text { Apoptosis } \\
\text { Mitochondrion } \\
\text { Sexual reproduction }\end{array}$ & $\begin{array}{l}\text { Mitochondrion } \\
\text { Amine catabolic } \\
\text { process } \\
\text { Ion transport } \\
\text { Glycolysis } \\
\text { Response to } \\
\text { metal ions } \\
\text { Carboxypeptidase } \\
\text { activity } \\
\text { ATP binding } \\
\text { Protein complex } \\
\text { assembly } \\
\text { Fatty acid metabolism } \\
\text { Metallopeptidase } \\
\text { activity }\end{array}$ & $\begin{array}{l}\text { Regulation of } \\
\text { response to stimulus } \\
\text { Lymphocyte activation } \\
\text { Extracellular region } \\
\text { Regulation of cell } \\
\text { activation } \\
\text { Cytoskeleton } \\
\text { Fatty acid binding } \\
\text { Calmodulin binding } \\
\text { Myofibril assembly } \\
\text { Angiogenesis } \\
\text { Cell adhesion }\end{array}$ & $\begin{array}{l}\text { Extracellular region } \\
\text { Response to hormone } \\
\text { stimulus } \\
\text { Cell adhesion }\end{array}$ & $\begin{array}{l}\text { Cell adhesion } \\
\text { Mitochondrion } \\
\text { ATP binding } \\
\text { ECM-receptor } \\
\text { interaction } \\
\text { Muscle contraction } \\
\text { Amino acid transport } \\
\text { Ion transport } \\
\text { Lipid transport }\end{array}$ & $\begin{array}{l}\text { Epidermal } \\
\text { development } \\
\text { Glycoprotein } \\
\text { metabolic processes } \\
\text { Structural molecule } \\
\text { activity } \\
\text { Cell cycle }\end{array}$ \\
\hline
\end{tabular}

Major items with an enrichment score $>1.0$ were selected.

Over-representation analyses were performed to map the enriched functional terms for specific secreted and membrane proteins. The results showed that specific secreted proteins in cancer tissues mainly functioned as peptidase and peptidase inhibitors, and had growth factor activity, performing the main biological processes of cell motility, response to external 
stimulus, and tissue development. Secreted proteins in normal tissues mainly functioned as receptors, peptidases, and lipid transporters, which corresponded primarily to the biological processes of cell motility, cell proliferation, and hormone metabolic processes. Analysis of membrane proteins in cancers showed the enriched functions of transmembrane transporter and signaling receptor activity, which are mainly involved in the processes of cell adhesion and transport. In normal tissues, specific membrane proteins had the enriched molecular functions of peroxidases, cargo receptor activity, and carbohydrate binding, and are involved in hormone metabolic and cellular homeostasis.

\section{DISCUSSION}

Cancer biomarkers represent key targets in the field of cancer research, because of their potential utilization in early cancer detection, diagnosis, and monitoring of response to treatment. A comprehensive analysis of human cancer-associated proteins and cancer-specific proteins might facilitate the understanding of the underlying mechanisms of carcinogenesis and the discovery of cancer biomarkers (Liu et al., 2012a,b).

In the present study, we constructed comprehensive differentially expressed protein profiles associated with different cancer types by quantitatively comparing credible immunohistochemistry results between normal and corresponding cancer tissues. Normal and cancer tissue-specific proteins were further screened across different tissue types. The results provided new insights into the research of cancer biology, and useful information for cancer biomarker discovery.

To investigate the underlying mechanisms of cancer development and progression, differentially expressed proteins in each cancer type were identified. Up-regulated proteins in cancers are predicted to play promising roles in understanding tumorigenesis and biomarker discovery. Thus, functional clustering analyses were performed to investigate the underlying common and special functions enriched by up-regulated proteins in each cancer type. Different functional clusters were identified in various cancers, which might indicate the different underlying mechanisms in cancer development and progression. However, several functions were commonly clustered in the cancers, including cell cycle, mitochondrion, cytoskeleton, cell adhesion, protein localization, and tight junction. These functions have previously been shown to be involved in cancer progression (Wallace, 2012; Williams and Stoeber, 2012), invasion (Behrens, 1993), and metastasis (Martin et al., 2011).

Tissue-specific proteins may also be involved in the key pathways associated with cancer development and progression, leading to different functions and biological processes among various tissues. These could be used as a unique tissue/cancer signature to distinguish among different tissue types or reflect disease state (Emig and Albrecht, 2011). In the present study, we screened the normal and cancer tissue-specific proteins among 14 different tissues. Some well-known tissue-specific proteins were also identified, such as ESR1 in breast cancer, shown to be associated with high grade and high proliferation (Moelans et al., 2010), CDX2 in colorectal cancer, used as a highly sensitive and specific marker of adenocarcinomas of intestinal origin (Werling et al., 2003), KLK2 and KLK3 in prostate cancer, utilized as biomarkers (Penney et al., 2011), and ACPP and FOLH1, identified as prostate-specific cancer proteins (Maraj and Markham, 1999). Of the 14 tissues examined, thyroid cancer tissue has the highest number of cancer tissue-specific proteins (103), including the well-known thyroid specific proteins TG and TPO (González et al., 2002). Of the normal tissues, the testis has the largest number of 
tissue-specific proteins, which reflects the complex protein expression and regulation in the testis (Liu et al., 2011, 2012c; Hua et al., 2013). These proteins may be potential cancer biomarkers and/or physiologic treatment targets, and further studies are warranted to evaluate their underlying functions.

Secreted proteins can serve as biomarkers for early cancer detection and diagnosis, and membrane proteins may be potentially effective therapeutic targets (Arcinas et al., 2009; Stastna and Van Eyk, 2012). Due to the fact that the highly abundant proteins comprise $99 \%$ of the total protein mass in the blood (Loo et al., 2010), the discovery of poorly expressed cancer-specific proteins in the blood by routine biotechnology becomes difficult. It is hypothesized that potential protein biomarkers could be secreted or shed directly into the bloodstream, allowing the evaluation of their concentrations in cancer patients (Prassas et al., 2012), thus discovery and verification of circulating cancer biomarkers by indirect identification and subcellular localization analysis of tissue-specific proteins become effective alternative methods. In the present study, secreted and membrane proteins were screened using Membrane Organization tools (http://locate.imb.uq.edu.au/). Expression levels of these proteins in the blood were verified between normal and cancer patients. Interestingly, these secreted proteins primarily belonged to the endogenous ligand gene family, which could bind to their receptors to trigger signals that affect specific cell development and function. The membrane proteins were primarily solute carriers, which have vital roles in cancer by transporting macromolecules and serving as potential treatment targets (El-Gebali et al., 2013).

As described in our previous studies (Liu et al., 2011, 2012c), some testis-specific proteins could become cancer/testis antigens specifically expressed in certain cancers. These proteins could be used as potential cancer vaccine targets. Notably, 24 proteins with specific testicular expression in the present study were commonly highly expressed in pancreatic and stomach cancers. The results indicated that these two gastric cancers might share certain common underlying mechanisms.

In conclusion, we performed a new strategy to identify candidate cancer-associated and cancer-specific proteins for utilization in future biomarker discovery studies. By comparing protein expression levels of 14 normal tissues with their corresponding cancer tissues, we identified candidate proteins and performed functional analyses. Further studies are warranted to validate the candidates and to substantiate the enriched functions identified herein. The results could be used as a reliable resource to study underlying carcinogenesis mechanisms and discover potential cancer targets for early diagnosis, therapeutic targets, and disease response markers.

\section{ACKNOWLEDGMENTS}

Research supported by grants from the National Natural Science Foundation of China (\#81300533) and the Shandong Provincial Natural Science Foundation, China (\#ZR2013HQ002).

\section{REFERENCES}

Arcinas A, Yen TY, Kebebew E and Macher BA (2009). Cell surface and secreted protein profiles of human thyroid cancer cell lines reveal distinct glycoprotein patterns. J. Proteome Res. 8: 3958-3968. 
Behrens J (1993). The role of cell adhesion molecules in cancer invasion and metastasis. Breast Cancer Res. Treat. 24: 175-184.

Brinton LT, Brentnall TA, Smith JA and Kelly KA (2012). Metastatic biomarker discovery through proteomics. Cancer Genom. Proteom. 9: 345-355.

Capaccione KM and Pine SR (2013). The Notch signaling pathway as a mediator of tumor survival. Carcinogenesis 34: $1420-1430$.

El-Gebali S, Bentz S, Hediger MA and Anderle P (2013). Solute carriers (SLCs) in cancer. Mol. Aspects Med. 34: 719-734.

Emig D and Albrecht M (2011). Tissue-specific proteins and functional implications. J. Proteome Res. 10: 1893-1903.

González C, Hernando M, Cava F, Herrero E, et al. (2002). Biological variability of thyroid autoantibodies (anti-TPO and anti-Tg) in clinically and biochemically stable patients with autoimmune thyroid disease. J. Clin. Lab. Anal. 16: 37-39.

Heckman-Stoddard BM (2012). Oncology biomarkers: discovery, validation, and clinical use. Semin. Oncol. Nurs. 28: 93-98.

Honda K, Ono M, Shitashige M, Masuda M, et al. (2013). Proteomic approaches to the discovery of cancer biomarkers for early detection and personalized medicine. Jpn. J. Clin. Oncol. 43: 103-109.

Hua XF, Wang XB and Liu FJ (2013). Functional analysis of human cancer-associated genes and their association with the testes and epididymis. Oncol. Lett. 6: 811-816.

Issaq HJ, Waybright TJ and Veenstra TD (2011). Cancer biomarker discovery: Opportunities and pitfalls in analytical methods. Electrophoresis 32: 967-975.

Liu F, Jin S, Li N, Liu X, et al. (2011). Comparative and functional analysis of testis-specific genes. Biol. Pharm. Bull. 34: $28-35$.

Liu FJ, Hua XF and Wang WJ (2012a). A new bioinformatics insight into human cancer-associated proteins. Oncol. Rep. 27: 1932-1936.

Liu FJ, Shao-Hua J and Xiao-Fang S (2012b). Differential proteomic analysis of pathway biomarkers in human breast cancer by integrated bioinformatics. Oncol. Lett. 4: 1097-1103

Liu FJ, Hai-Yan W and Jian-Yuan L (2012c). A new analysis of testicular proteins through integrative bioinformatics. Mol. Biol. Rep. 39: 3965-3970.

Loo JA, Yan W, Ramachandran P and Wong DT (2010). Comparative human salivary and plasma proteomes. J. Dent. Res. 89: 1016-1023.

Maraj BH and Markham AF (1999). Prostate-specific membrane antigen (FOLH1): recent advances in characterising this putative prostate cancer gene. Prostate Cancer Prostatic Dis. 2: 180-185.

Martin TA, Mason MD and Jiang WG (2011). Tight junctions in cancer metastasis. Front. Biosci. 16: 898-936.

Moelans CB, Monsuur HN, de Pinth JH, Radersma RD, et al. (2010). ESR1 amplification is rare in breast cancer and is associated with high grade and high proliferation: a multiplex ligation-dependent probe amplification study. Anal. Cell Pathol. 33: 13-18.

Ordóñez NG (2013). Application of immunohistochemistry in the diagnosis of epithelioid mesothelioma: a review and update. Hum. Pathol. 44: 1-19.

Penney KL, Schumacher FR, Kraft P, Mucci LA, et al. (2011). Association of KLK3 (PSA) genetic variants with prostate cancer risk and PSA levels. Carcinogenesis 32: 853-859.

Polanski M and Anderson NL (2007). A list of candidate cancer biomarkers for targeted proteomics. Biomark. Insights 1: $1-48$.

Pontén F, Schwenk JM, Asplund A and Edqvist PH (2011). The Human Protein Atlas as a proteomic resource for biomarker discovery. J. Intern. Med. 270: 428-446.

Prassas I, Chrystoja CC, Makawita S and Diamandis EP (2012). Bioinformatic identification of proteins with tissuespecific expression for biomarker discovery. BMC Med. 10: 39.

Stastna M and Van Eyk JE (2012). Secreted proteins as a fundamental source for biomarker discovery. Proteomics 12: $722-735$.

Wallace DC (2012). Mitochondria and cancer. Nat. Rev. Cancer 12: 685-698.

Werling RW, Yaziji H, Bacchi CE and Gown AM (2003). CDX2, a highly sensitive and specific marker of adenocarcinomas of intestinal origin: an immunohistochemical survey of 476 primary and metastatic carcinomas. Am. J. Surg. Pathol. 27: 303-310.

Williams GH and Stoeber K (2012). The cell cycle and cancer. J. Pathol. 226: 352-364. 